\title{
Effective stresses in a porous seabed of finite thickness: inertia effects
}

\author{
D.S. Jeng and M.S. Rahman
}

\begin{abstract}
The evaluation of wave-induced pore pressure and effective stresses is an important factor in the design of offshore installations. However, to simplify a complicated problem, most previous investigations have ignored the effects of inertia forces. This paper presents a new semi-analytical solution to the equations governing the wave-induced seabed response, including inertia terms for the whole problem. The numerical results show that the inertia forces cannot always be ignored. The relative difference between the present solution (with inertia items) and the previous solution (without inertia items) may reach $17 \%$ of $p_{\mathrm{o}}$ under certain combinations of wave and soil conditions.
\end{abstract}

Key words: inertia force, pore pressure, effective stresses.

Résumé: L'évaluation de la pression interstitielle et des contraintes effectives induites par les vagues est un facteur important dans la conception des installations offshore. Cependant, pour simplifier le problème complexe, la plupart des investigations antérieures ont ignoré les effets des forces d'inertie. Cet article présente une nouvelle solution semi-analytique des équations régissant la réponse du fond de la mer aux vagues induites, incluant les termes d'inertie dans l'ensemble du problème. Les résultats numériques montrent que les forces d'inertie ne peuvent pas toujours être ignorées. La différence relative entre la solution actuelle (avec les considérations d'inertie) et la solution antérieure (sans considération d'inertie) peut atteindre $17 \%$ de $p_{\mathrm{o}}$ avec certaines combinaisons de conditions de vagues et de sols.

Mots clés: force d'inertie, pression interstitielle, contraintes effectives.

[Traduit par la Rédaction]

\section{Introduction}

Recently, the phenomenon of wave-seabed interaction has been extensively studied by geotechnical and coastal engineers. The major reason for the growing interest in this problem is that many offshore installations (such as breakwaters, pipelines, and platforms, etc.) have been reported to be damaged by the waveinduced seabed instability in the vicinity of structures, rather than from construction causes (Silvester and Hsu 1989).

When waves propagate over the ocean, they induce dynamic pressure fluctuations on the sea floor. These fluctuations further generate excess pore pressures and effective stresses, which have been recognized as dominant factors in causing the instability of a seabed (Rahman 1997). Thus, an evaluation of the wave-induced soil response (including pore pressure, effective stresses, and soil displacements) is of significant importance to marine geotechnical and coastal engineers involved in the design of foundations for offshore installations.

Based on Biot's theory (Biot 1941), numerous theories of wave-induced soil response have been developed since the early 1940's. Among these, Yamamoto et al. (1978) considered twodimensional progressive waves over an isotropic and homogeneous seabed of infinite thickness. This model has been further extended to a seabed of finite thickness as well as a layered seabed (Jeng 1997). In the past few years, some advances have

Received November 24, 1999. Accepted May 23, 2000.

Published on the NRC Research Press website on December 13, 2000.

D.S. Jeng. School of Engineering, Gold Coast Campus, Griffith University, PMB 50 Gold Coast Mail Centre, QLD 9726, Australia. M.S. Rahman. Department of Civil Engineering, North Carolina State University, Raleigh, NC 27695-7908, U.S.A. been made by including anisotropic soil behaviour and nonhomogeneity (Jeng 1997). None of these investigations have not considered the effects of inertia forces on the wave-induced seabed response. An analytical closed-form solution has been developed by the authors to investigate the inertia effects on the wave-induced seabed response in an infinite seabed (Jeng et al. 1999). However, it has been reported that seabed thickness plays an important role in the evaluation of seabed response (Jeng 1997). Thus, it is of interest to re-examine the inertia effects on soil response for a seabed of finite thickness.

The objective of this study is to examine the influence of inertia forces on the wave-induced seabed response. To do so, the inertia terms are included in the governing equations. Based on the theory proposed by Jeng (1997), a new semi-analytical solution for such a condition is derived in this paper. To simplify the complicated problem, the porous seabed is considered to be an isotropic homogeneous medium of finite thickness. Based on the newly derived solution, the influences of inertia forces on the wave-induced seabed response will be examined.

\section{Theoretical formulations}

\section{Governing equations}

A progressive wave propagating over a porous seabed of finite thickness is depicted in Fig. 1 . The wave crests are assumed to propagate in the positive $x$-direction, while the $z$-direction is measured positive upward from the seabed surface.

In this study, we treat the soil behaviour of soil as isotropic linear elastic. The applicability of linear elastic isotropic soil behaviour has been argued because most marine sediments display a certain degree of anisotropy. However, to have some basic understanding of the inertia effects on the wave-induced seabed response, linear elastic isotropic soil behaviour is acceptable as 
Fig. 1. Definition of wave-seabed interaction. SWL, still water level.

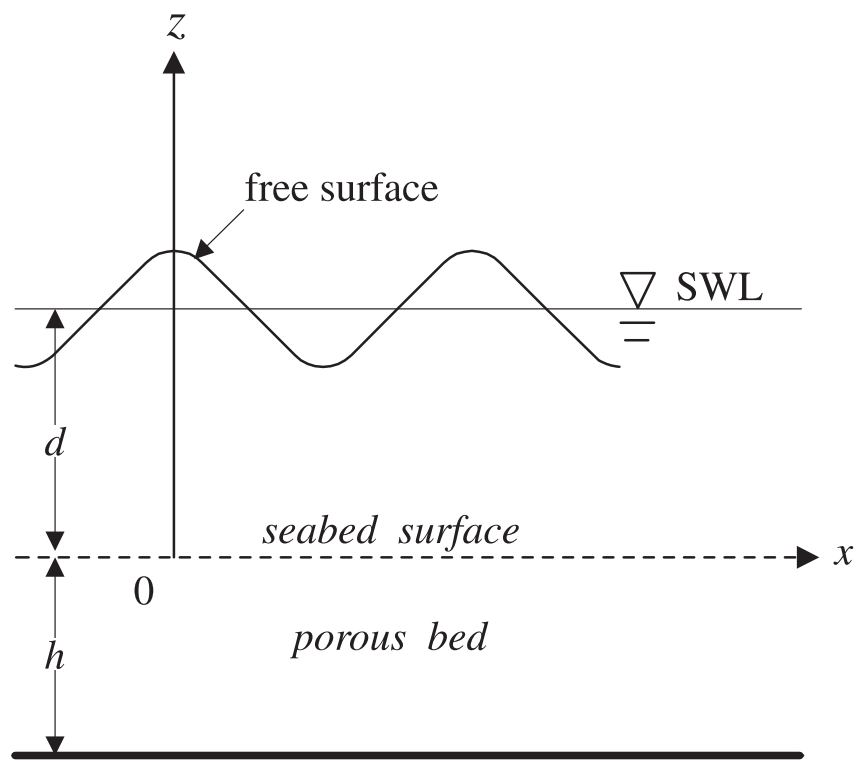

Rigid impermeable bottom

a first approximation. Certainly, this is the limitation of the present study.

For a two-dimensional wave-seabed interaction problem and treating the porous seabed as hydraulically isotropic with the same permeability, the consolidation equation (Biot 1941) can be expressed as

$$
\frac{K}{\gamma_{\mathrm{w}}}\left(\frac{\partial^{2} p}{\partial x^{2}}+\frac{\partial^{2} p}{\partial z^{2}}\right)-n \beta \frac{\partial p}{\partial t}+\rho_{\mathrm{f}} \frac{\partial^{2} \varepsilon}{\partial t^{2}}=\frac{\partial \varepsilon}{\partial t}
$$

where $K$ is soil permeability, $\gamma_{\mathrm{w}}$ is the unit weight of pore water, $n$ is soil porosity, $p$ is pore pressure, $t$ is the time, and $\rho_{\mathrm{f}}$ is the density of the pore fluid.

In eq. [1], the compressibility of pore fluid $(\beta)$ and the volumetric strain of the soil matrix $(\varepsilon)$ are defined by

$$
\beta=\frac{1}{K_{\mathrm{w}}}+\frac{1-S}{P_{\mathrm{wo}}} \quad \text { and } \quad \varepsilon=\frac{\partial u}{\partial x}+\frac{\partial w}{\partial z}
$$

in which $u$ and $w$ are soil displacements in the $x$ - and $z$-directions, respectively. $K_{\mathrm{w}}$ is the true modulus of elasticity of water (taken as $2 \times 10^{9} \mathrm{~N} / \mathrm{m}^{2}$, Yamamoto et al. 1978), $P_{\text {wo }}$ is the absolute water pressure, and $S$ is the degree of saturation. Although more comprehensive treatment of partially saturated soil has been reported in the literature, to simplify the complicated problem, we use eq. [2] to describe the unsaturation of the soil as suggested by Verrujit (1969).

Under the conditions of plane strains, the relationship between incremental effective stresses and soil displacements can be expressed as

$$
\sigma_{x}^{\prime}=2 G\left(\frac{\partial u}{\partial x}+\frac{\mu}{1-2 \mu} \varepsilon\right)
$$

$$
\sigma_{z}^{\prime}=2 G\left(\frac{\partial w}{\partial z}+\frac{\mu}{1-2 \mu} \varepsilon\right)
$$

$$
\tau_{x z}=G\left(\frac{\partial w}{\partial x}+\frac{\partial u}{\partial z}\right)=\tau_{z x}
$$

where $G$ is the shear modulus of the soil, $\mu$ is Poisson's ratio, and the shear stresses are expressed in double subscripts, $\tau_{x z}$, denoting the stress in the $z$-direction on a plane perpendicular to the $x$-axis. It is noted that a positive sign is taken for a tension normal stress in this study.

Based on the concept of effective stresses, the force equilibrium in the absence of body force within the soil skeleton can be expressed in terms of soil displacements and pore pressure as

$$
\begin{aligned}
& G\left(\frac{\partial^{2} u}{\partial x^{2}}+\frac{\partial^{2} u}{\partial z^{2}}\right)+\frac{G}{1-2 \mu} \frac{\partial \varepsilon}{\partial x}=\frac{\partial p}{\partial x}+\rho \frac{\partial^{2} u}{\partial t^{2}} \\
& G\left(\frac{\partial^{2} w}{\partial x^{2}}+\frac{\partial^{2} w}{\partial z^{2}}\right)+\frac{G}{1-2 \mu} \frac{\partial \varepsilon}{\partial z}=\frac{\partial p}{\partial z}+\rho \frac{\partial^{2} w}{\partial t^{2}}
\end{aligned}
$$

where $\rho\left(=(1-n) \rho_{\mathrm{s}}+n \rho_{\mathrm{f}} ; \rho_{\mathrm{S}}\right.$ is solid density and $\rho_{\mathrm{f}}$ is pore fluid density) is the density of the soil. It is noted that the second terms on the right-hand side of eqs. [6] and [7] are inertia forces, which have been ignored in most previous works (Yamamoto et al. 1978; Jeng 1997).

\section{Boundary conditions}

For a porous seabed of finite thickness, as shown in Fig. 1, the evaluation of the wave-induced seabed response requires the solution of eqs. [1], [6], and [7], together with the appropriate boundary conditions.

At the bottom of the seabed, zero displacements and no vertical flow occurs, i.e.,

$$
u=w=p=0 \text { as } z \rightarrow-\infty \text { for infinite thickness }
$$

$$
u=w=\frac{\partial p}{\partial z}=0 \text { as } z=-h \text { for finite thickness }
$$

We have assumed that the bottom frictional stress is small and negligible. At the seabed surface, the vertical effective normal stress and shear stress are zero and the pore pressure is equal to the wave pressure, i.e.,

$$
\begin{aligned}
& \sigma_{z}^{\prime}=\tau_{x z}=0 \\
& p=p_{0} \cos (k x-\omega t)=p_{0} \operatorname{Re}\left\{e^{i(k x-\omega t)}\right\} \text { at } z=0
\end{aligned}
$$

where $p_{\mathrm{o}}\left(=\gamma_{\mathrm{w}} H / \cosh k d ; H\right.$ is the wave height $)$ is the amplitude of wave pressure at the seabed surface, and $k$ is the wave number, which is defined by $2 \pi / L$ ( $L$ is the wavelength). In eq. [10], Re represents the real part of the function in brackets. 


\section{General solutions}

Since the wave-induced oscillatory soil response fluctuates periodically, the wave-induced pore pressure and soil displacements can be expressed as

$$
\left\{\begin{array}{c}
u(x, z ; t), \\
w(x, z ; t), \\
p(x, z ; t)
\end{array}\right\}=p_{\mathrm{o}}\left\{\begin{array}{c}
U(z) \\
W(z) \\
P(z)
\end{array}\right\} e^{i(k x-\omega t)}
$$

The wave-induced effective normal stresses and shear stresses can then be expressed as

$$
\begin{aligned}
& \sigma_{x}^{\prime}=\frac{2 G}{1-2 \mu}\left[i k(1-\mu) U+\mu W^{\prime}\right] e^{i(k x-\omega t)} \\
& \sigma_{z}^{\prime}=\frac{2 G}{1-2 \mu}\left[i k \mu U+(1-\mu) W^{\prime}\right] e^{i(k x-\omega t)} \\
& \tau_{x z}=G\left[2 i k W+a_{1} e^{\lambda_{1} z}+a_{2} e^{-\lambda_{1} z}\right] e^{i(k x-\omega t)}
\end{aligned}
$$

Following a similar procedure proposed by Jeng (1997) for the quasi-static solution, the wave-induced soil displacements and pore pressure can be expressed as

$$
\begin{aligned}
U(z)=\alpha_{4}\left(a_{1} e^{\lambda_{1} z}-a_{2} e^{-\lambda_{1} z}\right) & +\left(b_{1} e^{\lambda_{2} z}+b_{2} e^{-\lambda_{2} z}\right) \\
& +\left(c_{1} e^{\lambda_{3} z}+c_{2} e^{-\lambda_{3} z}\right)
\end{aligned}
$$

$$
\begin{aligned}
W(z)= & -\frac{i}{k}\left\{\left(\lambda_{1} \alpha_{4}-1\right)\left(a_{1} e^{\lambda_{1} z}+a_{2} e^{-\lambda_{1} z}\right)\right. \\
& +\lambda_{2}\left(b_{1} e^{\lambda_{2} z}-b_{2} e^{-\lambda_{2} z}\right) \\
& \left.+\lambda_{3}\left(c_{1} e^{\lambda_{3} z}-c_{2} e^{\lambda_{3} z}\right)\right\}
\end{aligned}
$$

$$
\begin{aligned}
P(z)= & \frac{-2 i G(1-\mu)}{k(1-2 \mu)}\left\{\delta_{1}\left(a_{1} e^{\lambda_{1} z}-a_{2} e^{-\lambda_{1} z}\right)\right. \\
& +\delta_{2}\left(b_{1} e^{\lambda_{2} z}+b_{2} e^{-\lambda_{2} z}\right) \\
& \left.+\delta_{3}\left(c_{1} e^{\lambda_{3} z}+c_{2} e^{-\lambda_{3} z}\right)\right\}
\end{aligned}
$$

where $\alpha$ and $\delta$ coefficients are given in the Appendix.

In eqs. [15]-[17], the six unknown coefficients, $a_{i}, b_{i}$, and $c_{i}$ $(i=1,2)$, can be solved numerically with the boundary conditions in eqs. [9]-[10]. Once the coefficients $\left(a_{i}, b_{i}\right.$, and $\left.c_{i}\right)$ are obtained, the wave-induced soil response can be further computed.

For a seabed of infinite thickness, to satisfy the bottom boundary condition eq. [8], $a_{2}, b_{2}$, and $c_{2}$ are equal to zero. Then, eqs. [15]-[17] can be easily rendered to the authors' previous work (Jeng et al. 1999).

\section{Numerical results}

The aim of this paper is to investigate the effects of inertia force on the wave-induced pore pressure, effective stresses, and soil displacements in a seabed of finite thickness, that is, the relative differences between the present solution with inertia forces and the previous solution without inertia forces (Jeng 1997). In fact, the influence of inertia force also depends on other soil and wave parameters (such as seabed thickness, degree of saturation, etc.). To have a basic understanding of the influence of inertia forces on soil response, we discuss inertia effects through a parametric study in the following sections.

\section{Effects of seabed thickness}

Figures 2 and 3 illustrate the vertical distribution of the maximum amplitudes of the wave-induced soil response (including pore pressure, effective normal stresses, shear stress, and soil displacements) versus the relative soil depth $(z / L)$ for various value of seabed thickness in coarse and fine sandy seabeds, respectively. In the figures, the solid lines represent the results of the present theory with inertia forces, and the dashed lines are the results of previous analytical solutions without inertia forces.

As seen in the figures, it is observed that the effects of inertia forces on the wave-induced horizontal effective normal stress $\left(\left|\sigma_{x}^{\prime}\right| / p_{0}\right)$ and vertical soil displacement $\left(|2 G k w| / p_{\mathrm{o}}\right)$ are significant in both coarse and fine sands. However, the waveinduced pore pressure $\left(|p| / p_{\mathrm{o}}\right)$, vertical effective normal stress $\left(\left|\sigma_{z}^{\prime}\right| / p_{0}\right)$, and shear stress $\left(\left|\tau_{x z}\right| / p_{0}\right)$ are only significantly affected by the inertia forces in a coarse sand, not in a fine sand. It is also observed that the wave-induced soil displacement in the horizontal direction is unaffected by inertia forces, as seen in Figs. 2 and 3. The figures clearly indicate that the maximum relative difference of pore pressure between the two solutions occurs near the seabed bottom in a coarse sand, while it occurs near the seabed surface in a fine sand.

It is worthwhile to point out that the inertia forces reduce the amplitude of the wave-induced pore pressure (Fig. 2). This implies that the excess pore pressure $\left(p-p_{\mathrm{b}}\right)$ will become larger under wave troughs and lead to a larger liquefaction depth near the wave troughs.

The contours of the wave-induced seabed response in saturated coarse and fine sands are illustrated in Figs. 4 and 5. The figures clearly indicate that the inertia forces not only affect the amplitude of the wave-induced seabed response, but also the distributions in spatial domain. For example, there is a phase lag between two solutions for pore pressure (e.g., Fig. 4a). This phenomenon becomes more significant in the horizontal effective stress and vertical soil displacements (e.g., Figs. $4 b$ and $4 f$ ).

\section{Effects of the degree of saturation}

It is common to find air/gas within marine sediments. It is believed that most marine sediments have degrees of saturation very close to unity, implying nearly full saturation (Pietruszczak and Pande 1996). It has been reported that the degree of saturation plays an important role in the analysis of the wave-induced seabed response. Thus, it is of interest to investigate the effects of inertia forces on the seabed response for various degrees of saturation values. 
Fig. 2. Vertical distribution of the maximum amplitude of $(a)|p| / p_{\mathrm{o}},(b)\left|\sigma_{x}^{\prime}\right| / p_{\mathrm{o}},(c)\left|\sigma_{z}^{\prime}\right| / p_{\mathrm{o}},(d)\left|\tau_{x z}\right| / p_{\mathrm{o}},(e)|2 G k u| / p_{\mathrm{o}}$, and $(f)$ $|2 G k w| / p_{0}$ versus relative soil depth $z / L$ for various seabed thicknesses $(h / L)$ in coarse sand. "_." denotes the present theory and " - - " denotes the results from Jeng (1997).
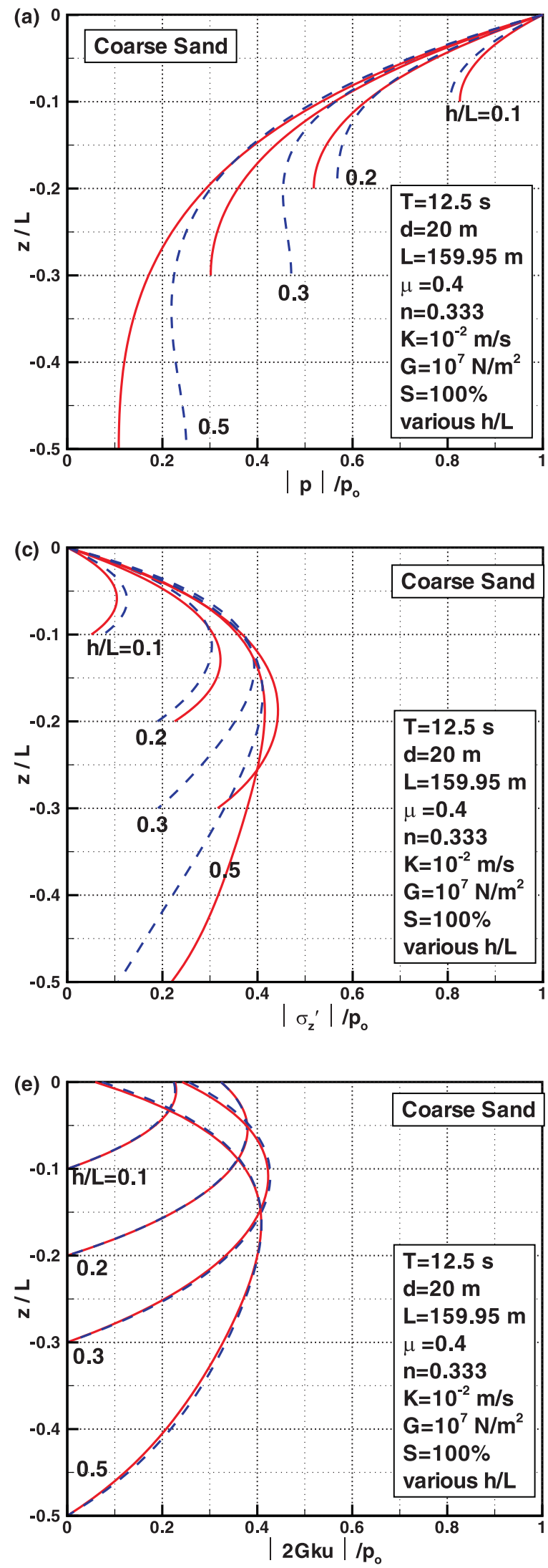
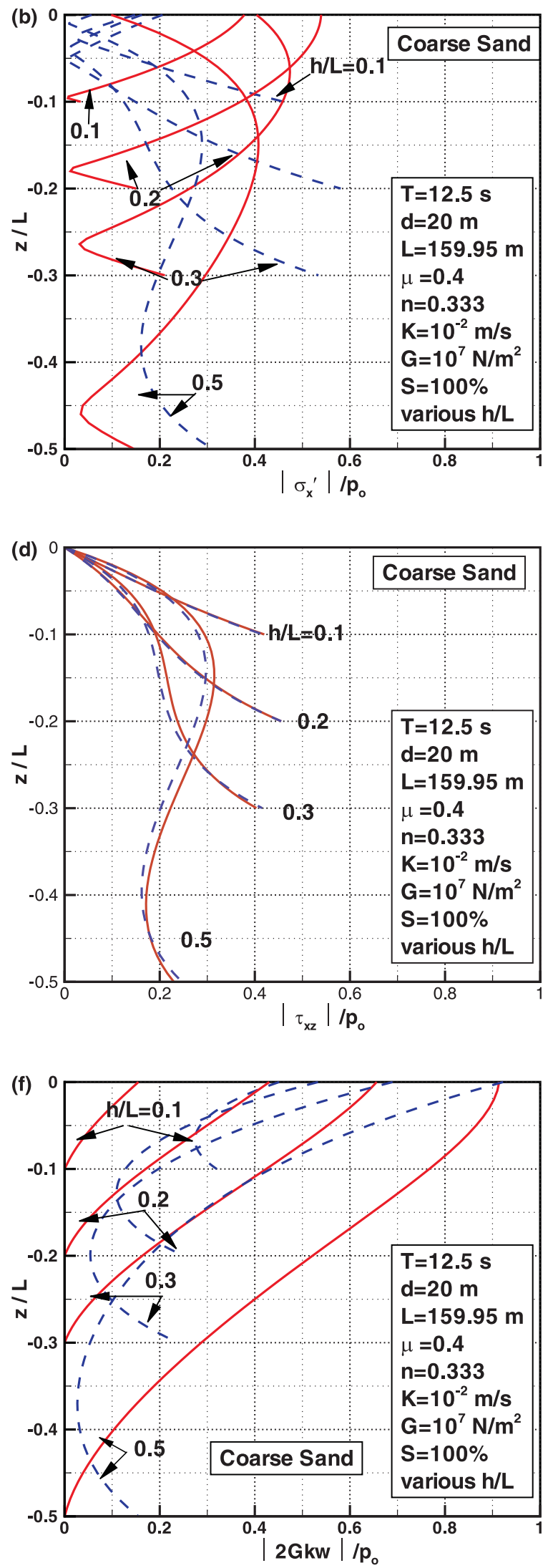

C2000 NRC Canada 
Fig. 3. Vertical distribution of the maximum amplitude of $(a)|p| / p_{\mathrm{o}},(b)\left|\sigma_{x}^{\prime}\right| / p_{\mathrm{o}},(c)\left|\sigma_{z}^{\prime}\right| / p_{\mathrm{o}},(d)\left|\tau_{x z}\right| / p_{\mathrm{o}},(e)|2 G k u| / p_{\mathrm{o}}$, and $(f)$ $|2 G k w| / p_{\mathrm{o}}$ versus relative soil depth $z / L$ for various seabed thicknesses $(h / L)$ in fine sand. "_-" denotes the present theory and " - - " denotes the results from Jeng (1997).
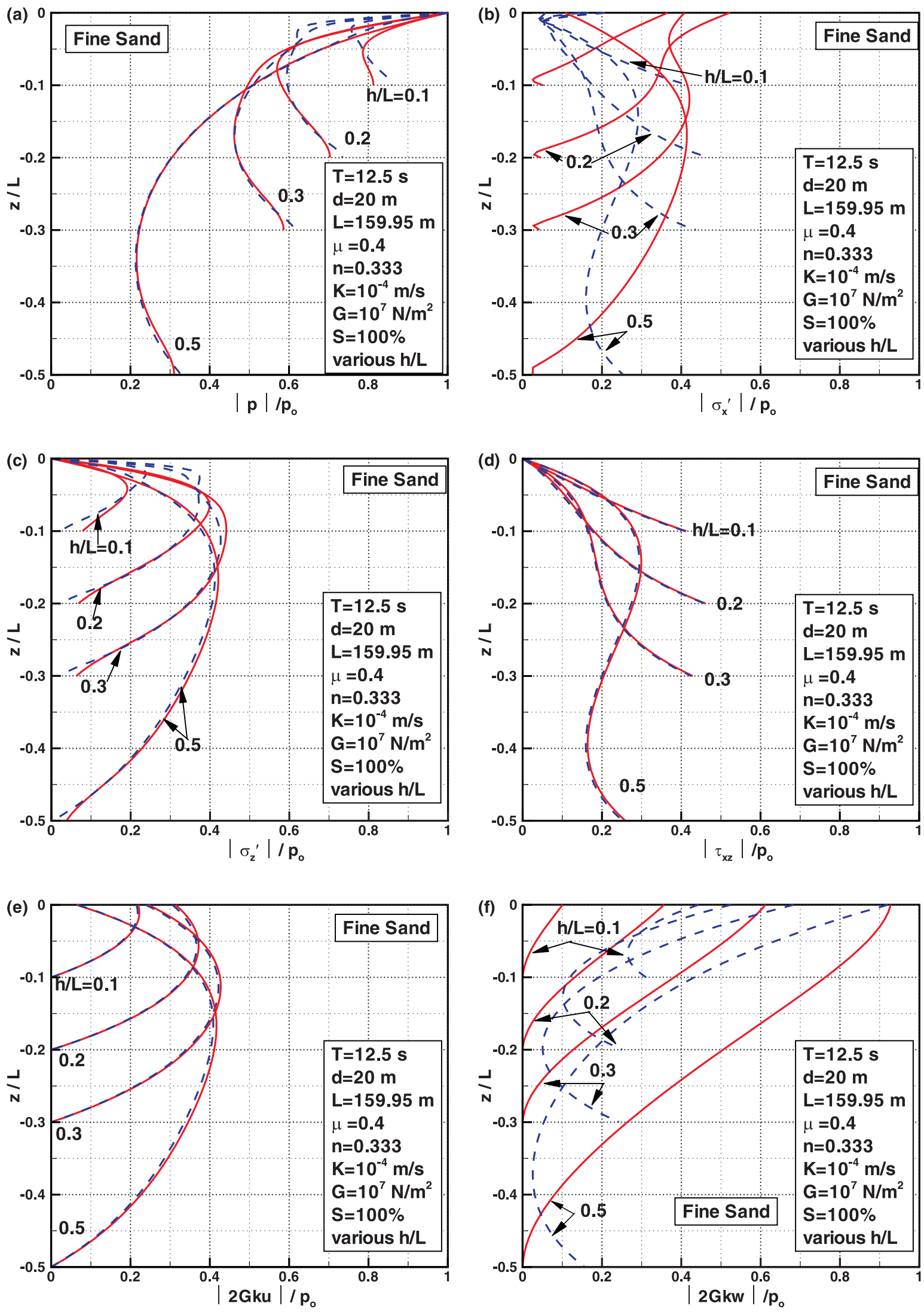
Fig. 4. Contours of the wave-induced $(a) p / p_{\mathrm{o}},(b) \sigma_{x}^{\prime} / p_{\mathrm{o}},(c) \sigma_{z}^{\prime} / p_{\mathrm{o}},(d) \tau_{x z} / p_{\mathrm{o}},(e) 2 G k u / p_{\mathrm{o}}$, and $(f) 2 G k w / p_{\mathrm{o}}$ in a saturated coarse sand. "_." denotes the present theory and " _ - " denotes the results from Jeng (1997). (h/L=0.2)

(a) $p / p_{0}: h / L=0.2$

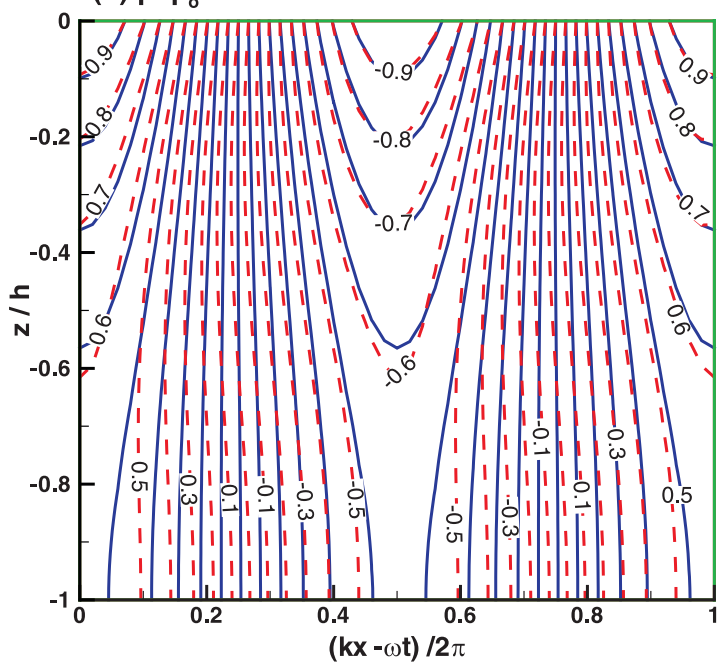

(c) $\sigma_{z}{ }^{\prime} / p_{0}: h / L=0.2$

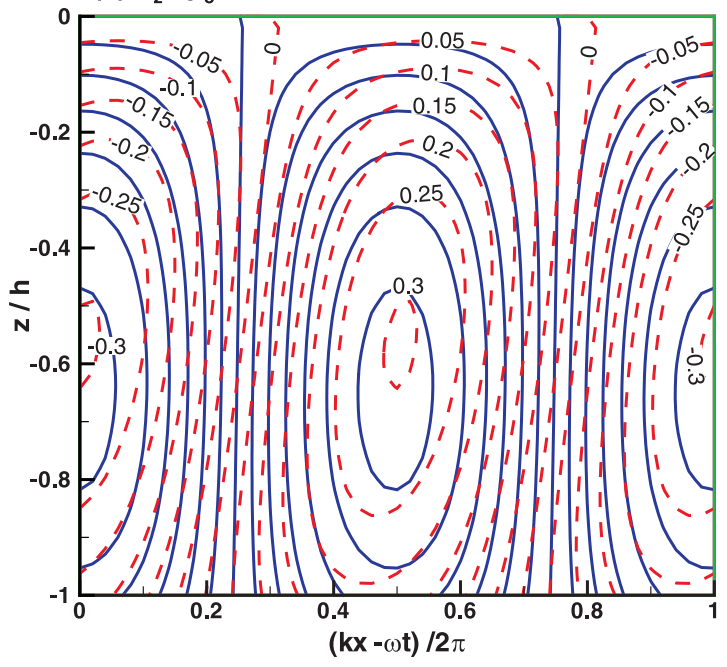

(e) $2 G k u / p_{0}: h / L=0.2$

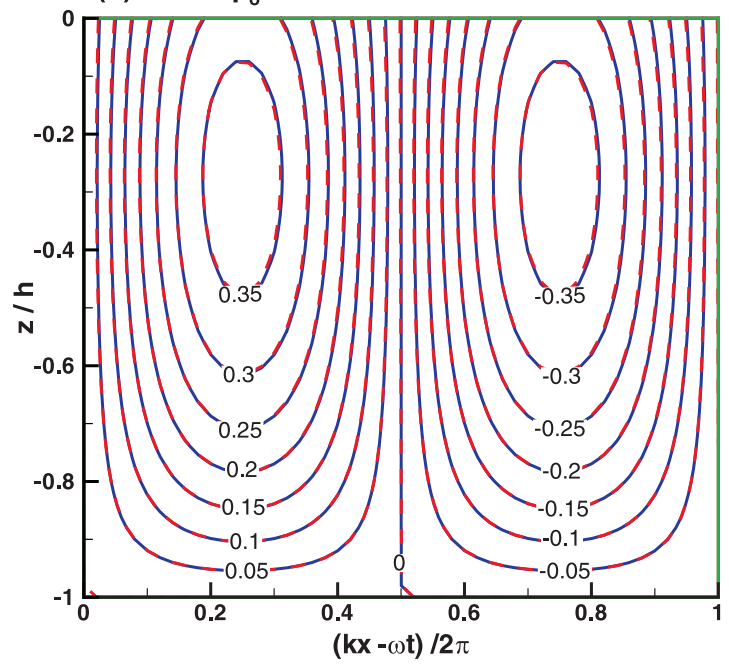

(b) $\sigma_{x}{ }^{\prime} / p_{o}: h / L=0.2$

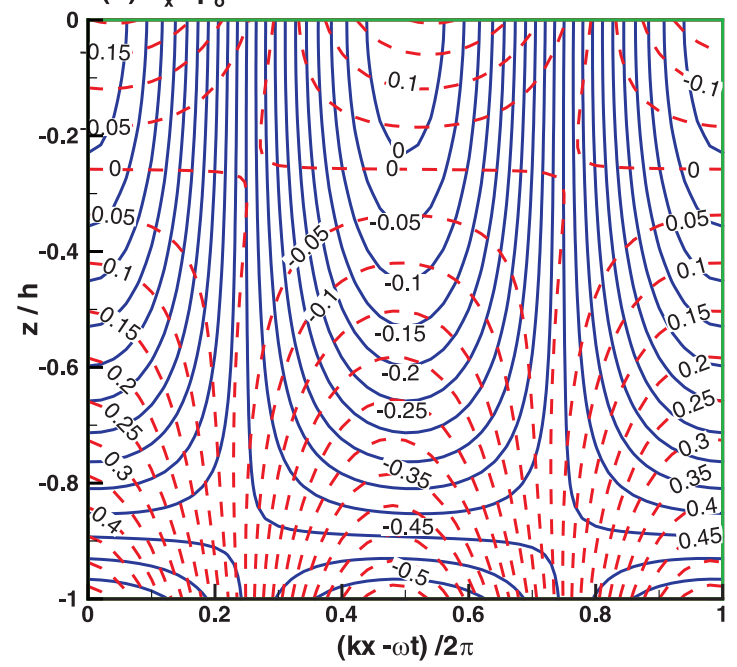

(d) $\tau_{x z} / p_{0}: h / L=0.2$

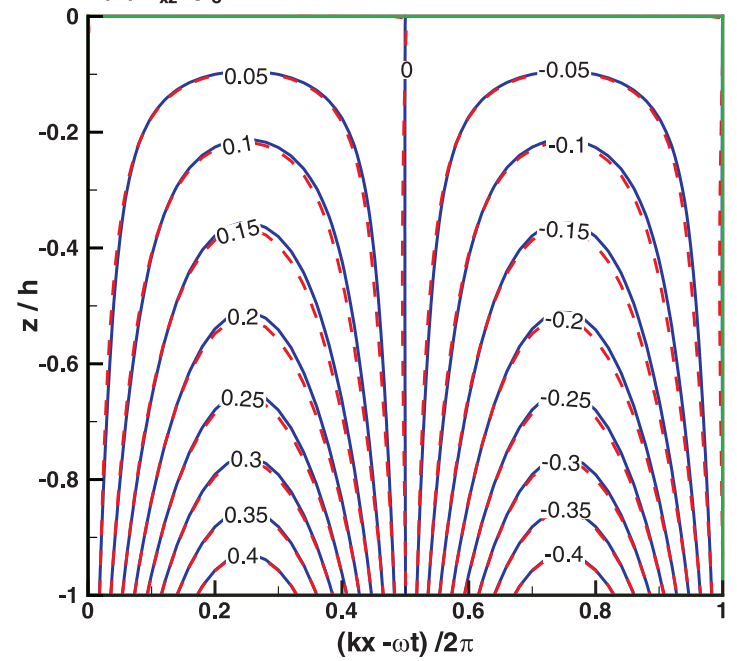

(f) $2 \mathrm{Gkw} / \mathrm{p}_{\mathrm{o}}: \mathrm{h} / \mathrm{L}=0.2$

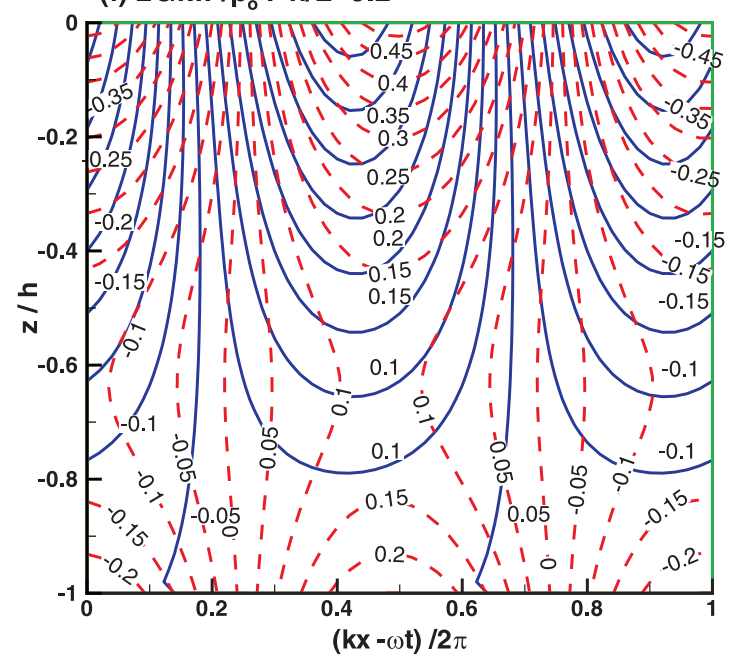


Fig. 5. Contours of the wave-induced $(a) p / p_{\mathrm{o}},(b) \sigma_{x}^{\prime} / p_{\mathrm{o}},(c) \sigma_{z}^{\prime} / p_{\mathrm{o}},(d) \tau_{x z} / p_{\mathrm{o}},(e) 2 G k u / p_{\mathrm{o}}$, and $(f) 2 G k w / p_{\mathrm{o}}$ in a saturated fine sand. "_" denotes the present theory and " - " denotes the results from Jeng (1997). $(h / L=0.2)$

(a) $\mathrm{p} / \mathrm{p}_{\mathrm{o}}: \mathrm{h} / \mathrm{L}=0.2$

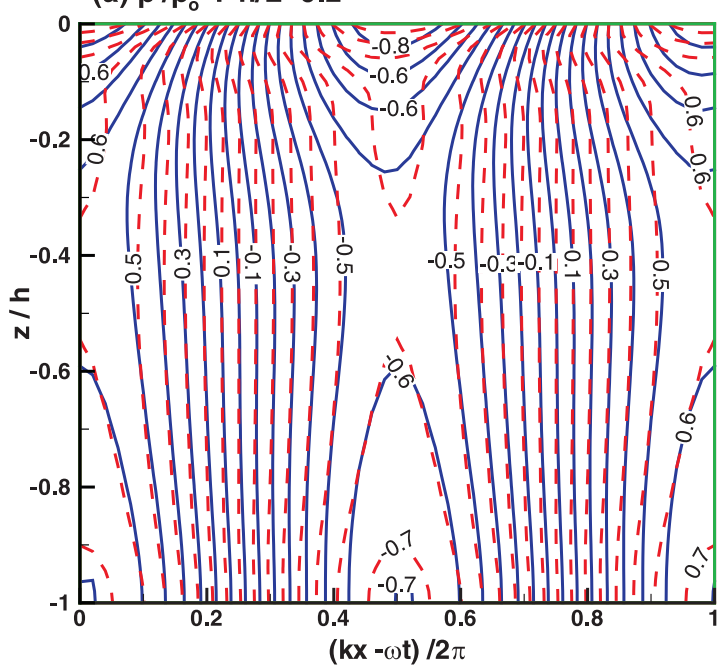

(c) $\sigma_{\mathrm{z}}{ }^{\prime} / \mathbf{p}_{\mathrm{o}}: \mathbf{h} / \mathrm{L}=0.2$

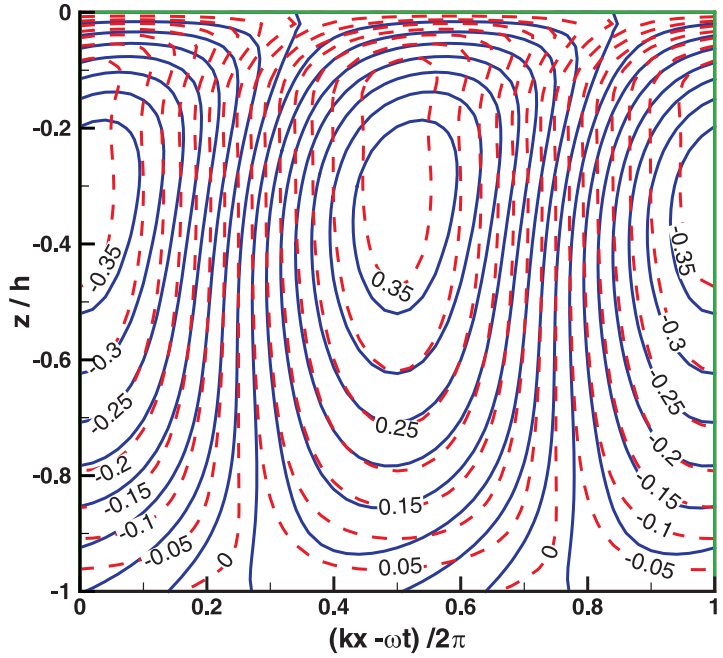

(e) $2 \mathrm{Gku} / \mathrm{p}_{\mathrm{o}}: \mathrm{h} / \mathrm{L}=0.2$

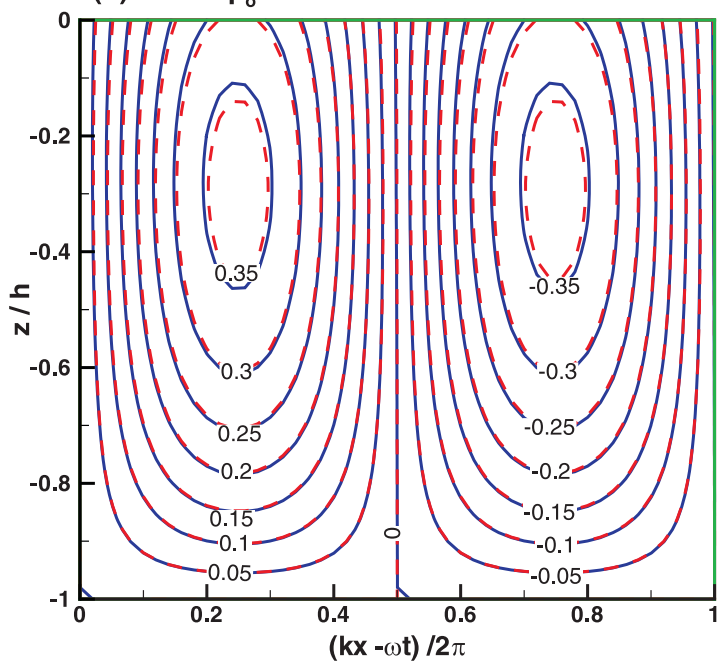

(b) $\sigma_{x}{ }^{\prime} / p_{0}: h / L=0.2$

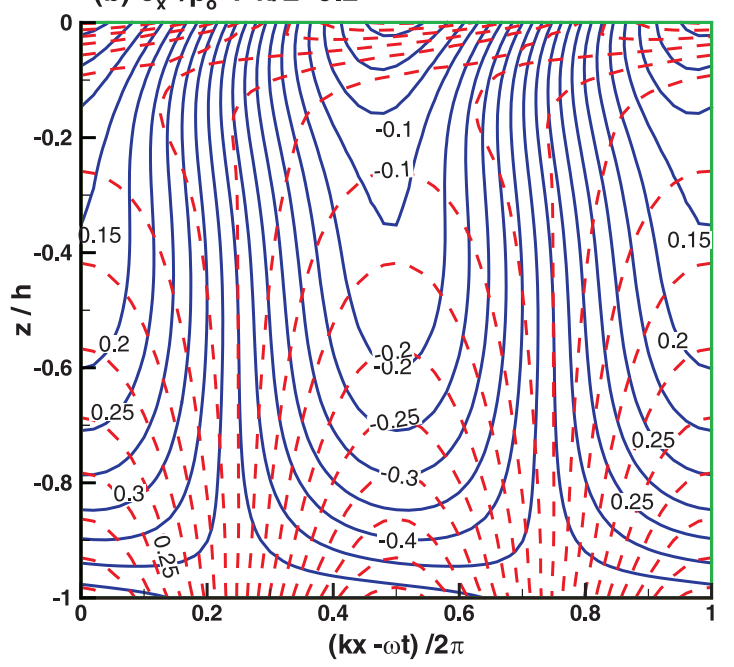

(d) $\tau_{x z} / p_{o}: h / L=0.2$

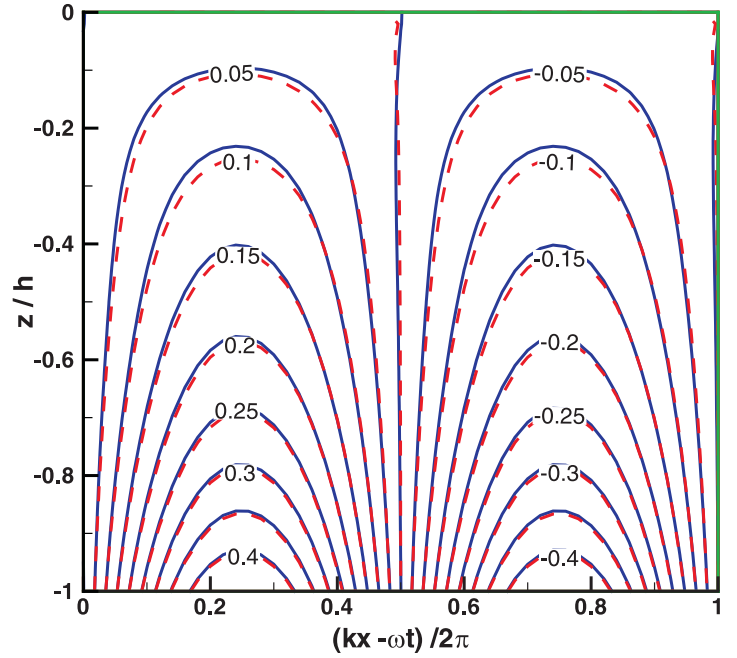

(f) $2 \mathrm{Gkw} / \mathrm{p}_{\mathrm{o}}: \mathrm{h} / \mathrm{L}=0.2$

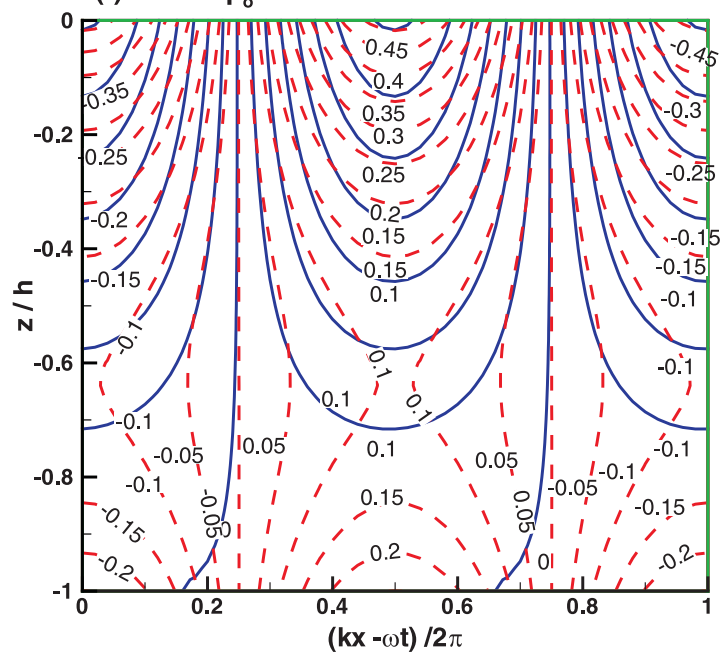


Fig. 6. Vertical distribution of the maximum amplitudes of the wave-induced pore pressure $\left(|p| / p_{\mathrm{o}}\right)$ versus the relative depth $(z / h)$ in coarse sand for various degrees of saturation. "-_" denotes the present theory and “ _ - " denotes the results from Jeng (1997).

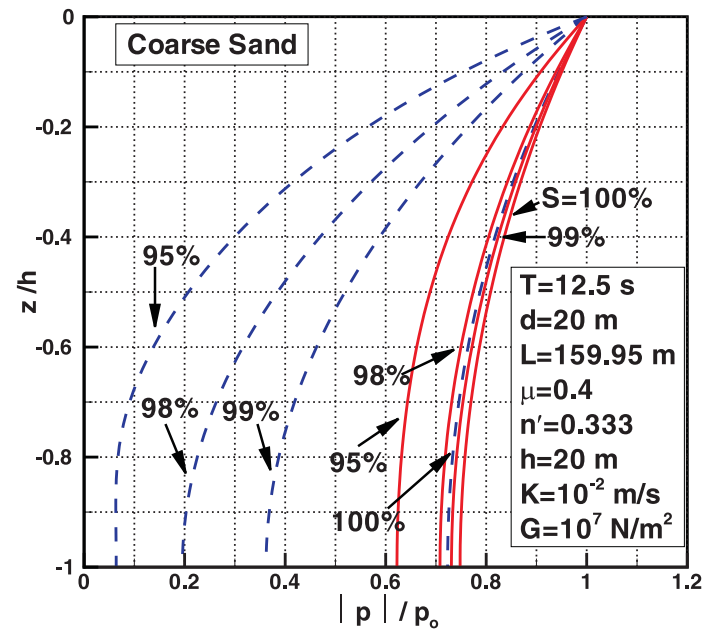

Fig. 7. Distribution of the relative difference of wave-induced pore pressure $\left(\Delta p / p_{\mathrm{o}}\right)$ versus the relative water depth $(d / L)$ for various seabed thicknesses $(h / L)$ in $(a)$ coarse sand and $(b)$ fine sand.
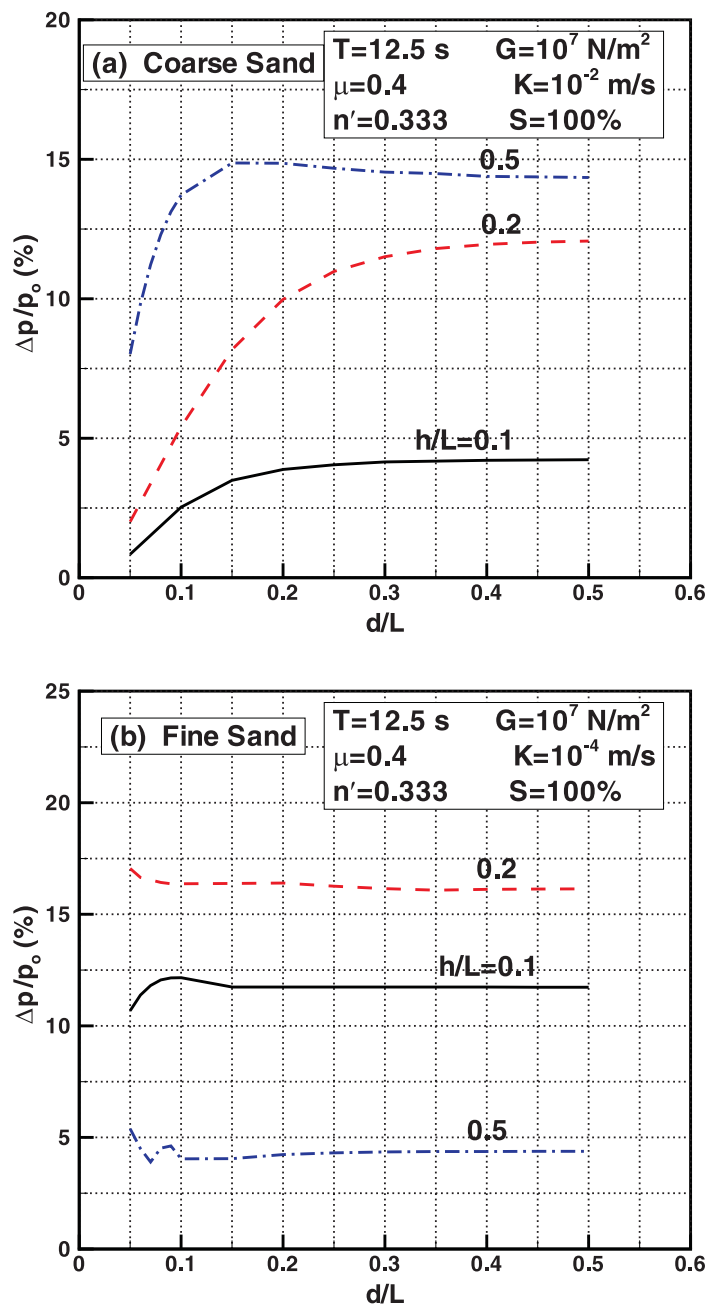

Figure 6 illustrates the wave-induced pore pressure $\left(|p| / p_{\mathrm{o}}\right)$ versus the relative soil depth $(z / h)$ for various degrees of saturation in a coarse sand. It can be found that the effects of saturation of the pore pressure with inertia forces (solid lines) may not be as important as that in the previous solution without inertia forces (dashed lines), especially in a nearly saturated seabed.

\section{Effects of soil permeability}

Soil permeability is an important parameter in soil mechanics, which describes how fast the pore fluid transfers through the pores between soil particles. In general, different values of soil permeability represent different materials. In this section, we will discuss the influences of soil permeability (in terms of coarse sand and fine sand) on the wave-induced seabed response.

Referring to Figs. 2-5, the major difference in soil characteristics between coarse sand and fine sand is soil permeability. Comparing Figs. 2 and 3 and Figs. 4 and 5, it is seen that the inertia effect affects the wave-induced soil response in coarse sand more significantly than in fine sand because the pore fluid is more easily transferred in coarse sand than in fine sand. This trend is more obvious in the magnitudes of $|p| / p_{\mathrm{o}},\left|\sigma_{z}^{\prime}\right| / p_{\mathrm{o}}$, and $|\tau| / p_{\mathrm{o}}$.

\section{When should we consider inertia forces?}

In engineering practice, it is important to find the relative differences of the wave-induced seabed response between two solutions (the present solution with inertia forces and the previous solution without inertia forces) and determine when we should consider inertia forces in the evaluation of the waveinduced seabed response.

Figure 7 presents the distribution of the relative differences of pore pressure $\left(|\Delta p| / p_{\mathrm{o}}=\left|p_{\text {inertia }}-p_{\text {noinertia }}\right| / p_{\mathrm{o}}\right)$ versus the relative water depth $(d / L)$ for various values of relative seabed thicknesses $(h / L)$ in both coarse and fine sands.

For a coarse sand (Fig. 7a), the relative differences of pore pressure between two solutions $\left(|\Delta p| / p_{0}\right)$ increases as $d / L$ increases and as relative seabed thickness $(h / L)$ increases. This implies that the inertia forces will become more important in the evaluation of the pore pressure in deep water for a coarse sand. This phenomenon becomes more obvious as $h / L$ increases.

For a fine sand (Fig. $7 b$ ), the trend of $|\Delta p| / p_{\mathrm{o}}$ is different from that in coarse sand. The maximum value of $|\Delta p| / p_{\mathrm{o}}$ occurs in shallow water (near $d / L=0.1$ ) and becomes almost a constant in middle and deep waters $(d / L>0.2)$. It is also noted that the relative difference of pore pressure $|\Delta p| / p_{\mathrm{o}}$ does not always increase as $h / L$ increases. The maximum value occurs at the relative soil depth $h / L=0.2$.

A possible explanation for the different trends between coarse and fine sands in Fig. 7 could be that the maximum value of $|\Delta p| / p_{\mathrm{o}}$ in course sand occurs near the seabed bottom (as seen in Fig. 2a) and it occurs near the seabed surface in fine sand (as seen in Fig. $3 a$ ). It is also noted that the maximum value of $|\Delta p|$ reaches $17 \%$ of $p_{\mathrm{o}}$ in fine sand (Fig. $7 b$ ), which is about three times that of the maximum value of $|\Delta p|$ in an infinite seabed as concluded from the authors' previous work (Jeng et al. 1999). This implies that the inertia forces cannot always be ignored at particular values of seabed thickness. 


\section{Conclusions}

In this study, inertia forces are included in the poro-elastic model for the wave-induced seabed response in a porous seabed of finite thickness. A new semi-analytical solution was derived here. Based on the numerical results presented, the following conclusions can be drawn:

(1) Generally speaking, the effects of inertia forces on pore pressure, effective stresses, and vertical soil displacements may be more significant under a certain combination of wave and soil conditions. The maximum value of the relative differences of pore pressure $(|\Delta p|)$ may be up to $17 \%$ of $p_{\mathrm{o}}$ (Fig. 7).

(2) The inertia forces do not only affect the magnitudes of the wave-induced seabed response, but also the spatial distribution. There is a phase lag in the distribution of the wave-induced seabed response between the present solution (with inertia forces) and the previous analytical solution (without inertia forces).

(3) The influence of the degree of saturation on the waveinduced seabed response will be reduced if the inertia forces are included in the wave-seabed interaction model.

(4) Comparing Figs. 2 and 3, the inertia effect is more important in coarse sand than in fine sand, due to higher permeability in coarser material.

(5) According to Fig. 7, it is found that the inertia forces may be more important in deeper water with larger seabed thickness in a coarse sand. However, the inertia forces will be more important in shallow water with $h / L=0.2$ in a fine sand.

\section{Acknowledgements}

The initial stage of the work described here forms part of the activities of the Special Research Centre for Offshore Found- ation Systems (COFS), The University of Western Australia (UWA), established and funded through the Australian Research Council's Special Centres Program. This study was initially established when the second author visited COFS/UWA in July 1998. The first author is also grateful for financial support from the Australian Academy of Science - National Science Council of Taiwan Scientists and Technologists Exchange Program in 1999 during his visit to Taiwan to finalize this work. The comments from reviewers are also appreciated.

\section{References}

Biot, M.A. 1941. General theory of three-dimensional consolidation. Journal of Applied Physics, 12(2): 155-164.

Jeng, D.S. 1997. Wave-induced seabed response in front of a breakwater. Ph.D. thesis, The University of Western Australia, Australia.

Jeng, D.S., Rahman, M.S., and Lee, T.L. 1999. Effects of inertia forces on wave-induced seabed response. International Journal of Offshore and Polar Engineering, 9(4): 307-313.

Pietruszczak, S., and Pande, G.N. 1996. Constitutive relations for partially saturated soils containing gas inclusions. Journal of Geotechnical Engineering, ASCE, 122(1): 50-59.

Rahman, M.S. 1997. Instability and movement of oceanfloor sediments: A review. International Journal of Offshore and Polar Engineering, 7(3): 220-225.

Silvester, R., and Hsu, J.R.C. 1989. Sines revisited. Journal of Waterways, Port, Coastal and Ocean Engineering, ASCE, 115(3): 327344.

Verruijt, A. 1969. Elastic storage of aquifers. In Flow through porous media. Edited by R.J.M. De Wiest. Academic Press, New York, pp. 331-376.

Yamamoto, T., Koning, H.L., Sellmeiher, H., and van Hijum, E.V. 1978. On the response of a poro-elastic bed to water waves. Journal of Fluid Mechanics, 87: 193-206.

\section{Appendix A: Mathematical derivation of general solutions}

In this appendix, the details of the mathematical derivation of the general solution will be given.

Substituting eq. [11] into eqs. [1], [6], and [7], the governing equations can be rewritten as

$$
\begin{aligned}
& \text { [A.1] } U^{\prime}-i k W=a_{1} e^{\lambda_{1} z}+a_{2} e^{-\lambda_{1} z} \\
& \text { [A.2] }\left\{\left(\frac{\partial^{2}}{\partial z^{2}}-k^{2}\right)\left(\frac{\partial^{2}}{\partial z^{2}}-k^{2}+\alpha_{1}^{2}\right)+\alpha_{2}^{2}\right\} U(z)=\frac{G k \lambda_{1} \alpha_{3}}{2(1-\mu)}\left(a_{1} e^{\lambda_{1} z}-a_{2} e^{-\lambda_{1} z}\right) \\
& \text { [A.3] } i k P=\frac{2 G(1-\mu)}{1-2 \mu}\left(U^{\prime \prime}-k^{2} U\right)+\rho \omega^{2} U-\frac{G \lambda_{1}}{1-2 \mu}\left(a_{1} e^{\lambda_{1} z}-a_{2} e^{-\lambda_{1} z}\right)
\end{aligned}
$$

where the $\alpha_{i}$ coefficients and $\lambda_{1}$ are given by

$$
\begin{aligned}
& \text { [A.4] } \lambda_{1}^{2}=k^{2}-\frac{\rho \omega^{2}}{G} \\
& \text { [A.5] } \alpha_{1}^{2}=\frac{i \omega \gamma_{\mathrm{w}}}{K}\left(n \beta+\frac{1-2 \mu}{2 G(1-\mu)}\right)+\frac{\left(k^{2}-\lambda_{1}^{2}\right)(1-2 \mu)}{2(1-\mu)}
\end{aligned}
$$


[A.6] $\quad \alpha_{2}^{2}=\frac{i \omega \gamma_{\mathrm{w}} n \beta(1-2 \mu)\left(k^{2}-\lambda_{1}^{2}\right)}{2 K(1-\mu)}$

[A.7] $\alpha_{3}=\left(\lambda_{1}^{2}-k^{2}\right)+\frac{i \omega \gamma_{\mathrm{w}} n \beta}{K}-\frac{i \omega(1-2 \mu)}{G K}\left[\gamma_{\mathrm{w}}+i \rho_{\mathrm{f}} \omega K\right]$

The general solution of eq. [A.2] can be written as

[A.8] $U(z)=\alpha_{4}\left(a_{1} e^{\lambda_{1} z}-a_{2} e^{-\lambda_{1} z}\right)+\left(b_{1} e^{\lambda_{2} z}+b_{2} e^{-\lambda_{2} z}\right)+\left(c_{1} e^{\lambda_{3} z}+c_{2} e^{-\lambda_{3} z}\right)$

which is eq. [15], and the $\alpha_{4}$ and $\lambda_{i}(i=2,3)$ coefficients are given as

[A.9] $\quad \alpha_{4}=\frac{\lambda_{1} \alpha_{3}}{2(1-\mu)} \frac{1}{\left(\lambda_{1}^{2}-k^{2}\right)\left(\lambda_{1}^{2}-k^{2}+\alpha_{1}^{2}\right)+\alpha_{2}^{2}}$

[A.10] $\lambda_{2}^{2}=\frac{1}{2}\left(-\alpha_{1}^{2}-\sqrt{\alpha_{1}^{4}-4 \alpha_{2}^{2}}+2 k^{2}\right)$

[A.11] $\lambda_{3}^{2}=\frac{1}{2}\left(-\alpha_{1}^{2}+\sqrt{\alpha_{1}^{4}-4 \alpha_{2}^{2}}+2 k^{2}\right)$

Then, substituting eq. [A.8] into eq. [A.1], it is easy to obtain the vertical soil displacement as

[A.12] $W(z)=-\frac{i}{k}\left\{\left(\lambda_{1} \alpha_{4}-1\right)\left(a_{1} e^{\lambda_{1} z}+a_{2} e^{-\lambda_{1} z}\right)+\lambda_{2}\left(b_{1} e^{\lambda_{2} z}-b_{2} e^{-\lambda_{2} z}\right)+\lambda_{3}\left(c_{1} e^{\lambda_{3} z}-c_{2} e^{\lambda_{3} z}\right)\right\}$

which is eq. [16].

Again, introducing eq. [A.8] into eq. [A.3], we can obtain the pore pressure as

[A.13] $P(z)=\frac{-2 i G(1-\mu)}{k(1-2 \mu)}\left\{\delta_{1}\left(a_{1} e^{\lambda_{1} z}-a_{2} e^{-\lambda_{1} z}\right)+\delta_{2}\left(b_{1} e^{\lambda_{2} z}+b_{2} e^{-\lambda_{2} z}\right)+\delta_{3}\left(c_{1} e^{\lambda_{3} z}+c_{2} e^{-\lambda_{3} z}\right)\right\}$

which is eq. [17], and the $\delta_{i}$ coefficients are given as

$\left[\right.$ A.14] $\delta_{1}=\frac{M\left(\lambda_{1}^{2}-k^{2}\right)-\lambda_{1}}{2(1-\mu)}$

$\left[\right.$ A.15] $\delta_{2}=\lambda_{2}^{2}-k^{2}+\frac{\left(k^{2}-\lambda_{1}^{2}\right)(1-2 \mu)}{2(1-\mu)}$

$\left[\right.$ A.16] $\delta_{3}=\lambda_{3}^{2}-k^{2}+\frac{\left(k^{2}-\lambda_{1}^{2}\right)(1-2 \mu)}{2(1-\mu)}$ 